\title{
Fatty Acids Composition of Red and Purple Pomegranate (Punica granatum L) Seed Oil
}

\author{
Hartati Soetjipto*, Murda Pradipta, KH Timotius \\ Department of Chemistry, Faculty of Science and Mathematic \\ Satya Wacana Christian University, Salatiga 50711. Indonesia
}

\begin{abstract}
The aim of this investigation was to determine the content and composition of fatty acid in seed oil of red and purple pomegranate (Punica granatum $L$ ). The extraction process was performed by Soxhlet extractor with petroleum ether as solvent. The separation and identification of pomegranate seed oil was done by using GCMS. The total oil content of red and purple pomegranate were $128 \mathrm{~g} / \mathrm{kg} \mathrm{d.w}$ and $103 \mathrm{~g} / \mathrm{kg} \mathrm{d.w}$ respectively. Both showed the same major fatty acids as palmitic, stearic, oleic, linoleic and punisic acid. Oleic acid ( $19-21 \%)$ and linoleic acid ( $20-21 \%$ ) were found as the most dominant fatty acids in red pomegranate, whereas purple pomegranate seed oil was dominated by oleic acid ( $4 I-43 \%)$ and punicic acid ( $0-25 \%)$. Neutral lipid fraction of red and purple pomegranate seed oils was more dominant than glycolipid and phospholipid. Neutral lipid fraction of red and purple pomegranate seed oil were $89 \%$ and $91 \%$ respectively. Glycolipid fraction of red and purple pomegranate seed oil were $8 \%$ and $5 \%$, whereas phosholipid fraction of red and purple pomegranate seed oil were $3 \%$ and $4 \%$. The punicic acid content of total lipid of purple pomegranate seed oil (PPSO) (0$25 \%$ ) was higher than red pomegranate (RPSO) (9-16\%). On the contrary neutral lipid of red pomegranate showed higher punicic acid content (54-75\%) than the purple pomegranate (14$55 \%)$. Glycolipid of red pomegranate contained punicic acid $(0-42 \%)$. The punicic acid content of the phospholipid fraction of red pomegranate was higher (0-22 \%) than the one of purple pomegranate $(0-2 \%)$.
\end{abstract}

Keywords: fatty acid, pomegranate, Punica granatum, punicic acid, seed oil.

\section{INTRODUCTION}

Pomegranate (Punica granatum L) which has a lot of seeds $50-70 \%$ per fruit, is a rich source of antioxidant. It has been linked to improve heart health and also indicates to protect against cancer (Hernandez, et al., 2002; Lansky and Newman, 2006). According to Sing et al., 2002, methanol extract of pomegranate seed oil showed the strong antioxidant effect.

The seed oil of pomegranate contain conjugated fatty acid (Conjugated Linolenic Acid/ CLA or punicic acid), which is showed a potential to prevent cancer and artheroschlerosis (Boussetta, et al., 2009). The antioxidant effect was exhibited by its CLA are being potential used in cosmetics as anti aging. The punicic acid containing seed oil can be obtained by Soxhlet extraction by using non polar solvent.
Based on fruits color there are three kinds of pomegranate ( $P$. granatum) were found in Indonesia, which are white, red and purple pomegranates. But in this study only red and purple pomegranate seed were used as the samples. The aim of this study is to determine the content and composition of fatty acid in seed oil of red and purple pomegranate (P.granatum), especially the punicic acid content.

\section{METHODS}

Samples of red and purple pomegranate seeds were collected from Tegal, Bandungan and Kopeng Salatiga, Central Java The seeds were crushed and oven-dried at $60^{\circ} \mathrm{C}$ for two days.

\footnotetext{
*Corresponding author e-mail : hartatis2003@yahoo.com
} 
Seed oil extraction process was performed by Soxhlet extractor using petroleum ether as solvent for 6 hours. The extracted oil was dried by $\mathrm{Na}_{2} \mathrm{SO}_{4}$ anhydrous, filtered and weighed to obtain the rendement.

Column chromatography was used to separate neutral lipid, glycolipid and phospholipid fraction with silica gel as stationary phase and chloroform, acetone and then methanol as mobile phase. The separated samples were evaporated and weighed, so that the percentage of neutral lipid, glycolipid and phospholipid fraction can be obtained.

The fatty acid identification of pomegranate seed oil was done by using GCMS (SHIMADZU QP2010S) after esterification to FAME. GCMS conditions were as follows: column Rtx-5MS (30 $\mathrm{m}$, ID $0.25 \mathrm{~mm}, 80^{\circ} \mathrm{C}-5^{\circ}$; injector: $300^{\circ} \mathrm{C}-34^{\prime}$; Helium as carrier gas, $16.5 \mathrm{Kpa}$, flow rate $0.50 \mathrm{ml} / \mathrm{min}$. MS: detector temperature $300^{\circ} \mathrm{C}, 3.00$ min.

\section{RESULTS}

The lipid content of red and purple pomegranate seed oil were $128 \mathrm{~g} / \mathrm{kg}$ d.w and 103 $\mathrm{g} / \mathrm{kg}$ d.w respectively. Total fatty acid of RPSO was higher than the one of PPSO. The oil color was clear yellow.

The total oil amount of neutral lipid, glycolipid and phospholipid fractions in both red and purple pomegranate showed similar pattern (Table 1). Neutral lipid was the highest and followed by glycolipid and phospholipid fraction.

The fatty acid composition of Red Pomegranate Seed Oil (RPSO) and Purple Pomegranate Seed Oil (PPSO) were compared and reported in Table 2 . The fatty acid composition of both showed six major fatty acids (Figure 1)

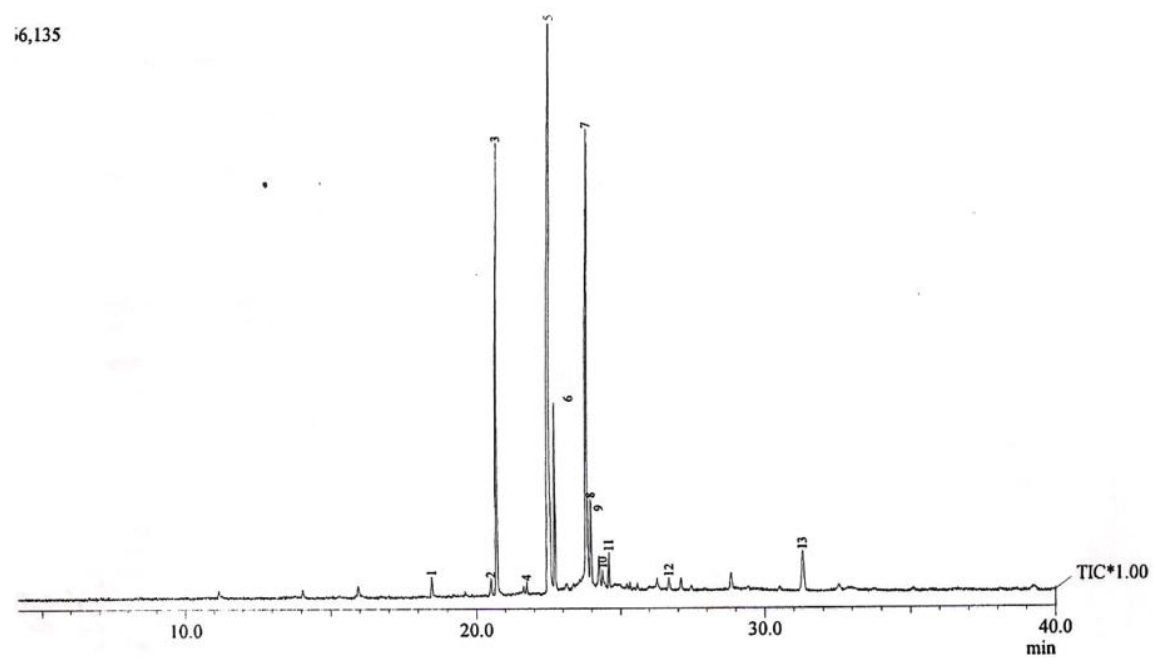

Figure I. GC-MS Chromatogram Purple Pomegranate Seed Oil

Note: peaks 3: palmitic acid; 5: oleic acid; 6. stearic acid; 7. linoleic acid; 8. punicic acid; 1,2,4, , 9 - 13 : minor fatty acids 
Table I. Lipid Content of Red and Purple Pomegranate Seed Oils (\%w/d.w)

\begin{tabular}{ccc}
\hline Composition & Red Pomegranate & Purple Pomegranate \\
\hline Neutral Lipid & 89 & 91 \\
Glycolipid & 8 & 5 \\
Phospholipid & 3 & 4 \\
Total & 100.00 & 100.00 \\
\hline
\end{tabular}

Table 2. Fatty Acid Composition of Red and Purple Pomegranate Seed Oils (\% w/d.w)

\begin{tabular}{|c|c|c|}
\hline Fatty acid & Red Pomegranate Seed Oil & $\begin{array}{c}\text { Purple Pomegranate Seed } \\
\text { Oil }\end{array}$ \\
\hline Palmitic Acid (Cl6-0) & $0-9$ & 17 \\
\hline Stearic Acid (CI8-0) & $9-11$ & $7-13$ \\
\hline Oleic Acid (CI8-In-9) & $|9-2|$ & $41-43$ \\
\hline Linoleic Acid (C।8:2n-6) & $20-21$ & $0-19$ \\
\hline Punicic Acid (CI8: 3n-5) & $9-16$ & $0-25$ \\
\hline Saturates & $9-20$ & 24-30 \\
\hline Mono-unsaturates & $|9-2|$ & $4 \mid-43$. \\
\hline Disaturates & $20-21$ & $0-19$ \\
\hline Tri-unsaturates & $9-16$ & $0-25$ \\
\hline Unsaturates & 48-58 & $41-87$ \\
\hline Saturates/unsaturates & $0.18-0.34( \pm 0.26)$ & $0.58-0.34( \pm 0.46)$ \\
\hline
\end{tabular}

Table 3. Fatty Acid Composition, Neutral Lipid, Glycolipid and Phospholipid of Red and Purple Pomegranate Seed Oils (\%w./d.w)

\begin{tabular}{|c|c|c|c|c|c|c|}
\hline \multirow[t]{2}{*}{ Fatty Acid } & \multicolumn{2}{|c|}{ Neutral Lipid } & \multicolumn{2}{|c|}{ Glycolipid } & \multicolumn{2}{|c|}{ Phospholipid } \\
\hline & $\begin{array}{l}\mathbf{R} \\
\end{array}$ & $\mathbf{P}$ & $\begin{array}{l}\mathbf{R} \\
\end{array}$ & $\mathbf{P}$ & $\mathbf{R}$ & $\mathbf{P}$ \\
\hline $\begin{array}{c}\text { Palmitic Acid } \\
\text { CI6-0 }\end{array}$ & $0-10$ & $6-12$ & $0-6$ & $11-24$ & $0-25$ & $35-38$ \\
\hline $\begin{array}{c}\text { Stearic Acid } \\
\text { CI8-0 }\end{array}$ & $3-6$ & $4-9$ & $0-10$ & $4-10$ & $10-12$ & $12-14$ \\
\hline $\begin{array}{l}\text { Oleic Acid } \\
\text { Cl8-In-9 }\end{array}$ & $8-11$ & $|9-2|$ & $7-14$ & $0-19$ & $14-34$ & $15-39$ \\
\hline $\begin{array}{l}\text { Linoleic Acid } \\
\text { CI8:2n-6 }\end{array}$ & $8-9$ & $0-25$ & $6-30$ & $0-32$ & $6-16$ & $0-29$ \\
\hline $\begin{array}{l}\text { Punicic Acid } \\
\text { C18: } 3 n-5\end{array}$ & $54-75$ & $14-55$ & $0-42$ & - & $0-22$ & $0-2$ \\
\hline
\end{tabular}

\section{DISCUSSION}

In accordance with the purpose of this study in determining the total lipid content and fatty acid composition of seed oil in red and purple pomegranates, we found that PPSO had higher content of total lipid than the one of RPSO. RPSO extraction were $\pm 128 \mathrm{~g} / \mathrm{kg}$ and PPSO was \pm 103 $\mathrm{g} / \mathrm{kg}$. These values were higher than the range described by Hernandez et al.

(2002), who reported the lipid content were approximately $70-80 \mathrm{~g} / \mathrm{kg}$ and $105 \mathrm{~g} / \mathrm{kg}$. This might be caused by the different origin of the plants.

The relative abundance of fatty acids of the PPSO and RPSO were similar: palmitic, stearic, oleic, linoleic and punicic acids. The area percentage of the above mentioned fatty acids were 
different between RPSO and PPSO. The major fatty acids in RPSO were linoleic acid (18:2) comprised $20-21 \%$ of the total fatty acid. Oleic acid (C18:1) comprised 19-21\% and punicic acid (C18:3) comprised 9-16\% of the total. The remaining fatty acids were mainly stearic acid (C18:0) comprised 9-11\%, and palmitic acid (C16:0) 0-9\% from the total. The main fatty acids of PPSO oleic acid (C18:1) comprised 41-43\% of the total fatty acid, punicic acid (C18:3) comprised $0-25 \%$. The remaining fatty acids were mainly linoleic acid (18:2) comprised 0-19\%, palmitic acid (C16:0) $17 \%$, and stearic acid (C18:0) comprised 7-13\% from the total.

Table 2 also showed that the total lipid of PPSO contain a higher punicic acid (0-25\%) than RPSO (9-16\%). These percentage were far under percentage (66-79\%) as reported by Hernandez et al. (2002). Many possibilities can influence to the result of experiment. In this study the differences of result were possible occurred due to the origin of the sample which used in this study come from e.g different place, climate and soil condition. Different places of sample will influence against plants compound composition (Inchbald, 2000). Another reason was probably different extraction methods gave different result.

The neutral lipid fraction of RPSO and PPSO showed higher punicic acid (54-75\% and $14-55 \%)$ than glycolipid and phospholipid. These value indicates that punicic acid can be extracted more than $50 \%$ in the neutral lipid fraction.

Concerning the ratio of saturated fatty acid/unsaturated fatty acid (Table1) were very different with the figure given by Hernandez et al. (2002). The diiferences could be understood because of the different punicic acid content, which was very important for the calculate of Saturated/unsaturated ratio.

\section{CONCLUSION}

1. The seed oils of red and purple pomegranate showed a similar main fatty acid composition such as palmitic acid, stearic acid, oleic acid, linoleic acid, punicic acid and eicosanoic acid.
2. Total lipid of red pomegranate seed oil was dominated by linoleic acid $(20-21 \%)$, oleic acid (19-21\%) and followed by punicic acid (9-16\%), stearic acid (9-11\%), palmitic acid ( $0-9 \%$ ), whereas the purple pomegranate seed oil showed oleic acid (41-43\%), punicic acid (0-25\%), followed by linoleic acid (0-19\%), palmitic acid (17\%), and stearic acid (7-13\%).

3. Total lipid of purple pomegranate seed oil have punicic acid content was higher than red pomegranate seed oil. Based on the below following fact, it could be concluded that seed oil of the purple variety was better than the red one.

\section{REFERENCES}

Boussetta, I., Raad, H., Lettéron, P., Pocidalo, M.A.G., Marie, J.C., Driss. F. and El-

Benna, J., 2009, Punicic Acid a Conjugated Linolenic Acid Inhibits TNFa-Induced Neutrophil Hyperactivation and Protects from Experimental Colon Inflammation in Rats, PLoS One.

Hernandez, F.P., Melgarejo, J.M., Olias, J.M. and Artes, F., 2002, Fatty Acid Composition and Total Lipid Content of Seed Oil from Three Commercial Pomegranate Cultivars, CHEAM-Options Mediteranenes, 205-209.

Inchbald, G., 2000, Fat content and Fatty Acid Compsition of Seed Oil. http://72.14.235. 104/search?q=cache:nyDs PP_t9qss:www.steelpillow.com/seedoils/in dex.htm+seed+oil+content\&hl=id\&ct=clnk $\& c d=|\& g|=i d$

Accessed on July 13, 2008.

Lansky, E.P. and Newman, R.A., 2006, Punica granatum (pomegranate) and Its Potential for Prevention and Treatment of Inflammation and Cancer, J. Ethnopharmacol 109, 177-206

Singh, R.P.K.N., Chidambara, M. and Jayaprakasha, G.K., 2002, Studies on The Antioxidant Activity of Pomegranate (Punica granatum) Peel and Seed Extracts Using in Vitro Models, J. Agric. Food Chem., 50, 8I-86. 